\title{
A multi-omics study to investigate tacrolimus
}

\section{nephrotoxicity mechanisms}

Hassan AOUAD ${ }^{1}$, Quentin FAUCHER ${ }^{1}$, François-Ludovic SAUVAGE ${ }^{1}$, Emilie PINAULT¹, Claire-Cécile BARROT ${ }^{1}$, Hélène ARNION ${ }^{1}$, Pierre MARQUET ${ }^{1,2 *}$, Marie $\mathrm{ESSIG}^{3 *}$

* These authors contributed equally

Primary laboratory of origin: U1248 IPPRITT, Université de Limoges, INSERM, Limoges, France

Affiliations:

HA, FLS, EP, QF, CCB, HA, PM and ME: U1248 IPPRITT, Université de Limoges, INSERM, Limoges, France

PM: Department of Pharmacology and Toxicology, CHU Limoges, Limoges, France ME: APHP Paris Saclay University, Ambroise Paré Hospital, Nephrology Departement, 92100 Boulogne Billancourt, France 


\section{Running title: Multi-omics investigation of tacrolimus nephrotoxicity}

\section{Corresponding author:}

Pierre Marquet, Service de Pharmacologie, Toxicologie et Pharmacovigilance, Centre Hospitalier Universitaire, 2 rue Martin Luther King, 87042 Limoges, France

Email: pierre.marquet@unilim.fr

Number of pages: 36

Number of figures: 8

Number of tables: 2

Number of references: 27

Number of words in the abstract: 207

Number of words in the introduction: 309

Number of words in the discussion: 1591

\section{Abbreviations:}

PCK-1: phosphoenolpyruvate carboxykinase 1; FBP1: Fructose biphosphatase 1; FBP2:

Fructose biphosphatase 2; LLC-PK1: Lilly Laboratories Cells Porcine Kidney 1; LC-MS/MS: liquid chromatography coupled to tandem mass spectrometry; MTS: 3-(4,5-dimethylthiazol2-yl)-5-(3-carboxymethoxyphenyl)-2-(4-sulfophenyl)-2H-tetrazolium; NADPH: Nicotinamide adenine dinucleotide phosphate; PCA: Principal component analysis. 


\section{Abstract}

Tacrolimus, prescribed to a majority of transplanted patients is associated with nephrotoxicity, the mechanism of which remains unclear. This study aims to evaluate the impact of tacrolimus on proximal tubular cells using a multi-omics approach. LLC-PK1 cells were exposed to $5 \mu \mathrm{M}$ of tacrolimus for $24 \mathrm{~h}$. Intracellular proteins and metabolites, and extracellular metabolites were extracted and analysed by LC-MS/MS. The transcriptional expression of PCK-1, FBP1 and FBP2 was measured using RT-qPCR. In our cell model, tacrolimus impacted different metabolic pathways including urea cycle (e.g., citrulline, ornithine) $(p<0.0001)$, amino acid metabolism (e.g., valine, isoleucine, aspartic acid) $(p<0.0001)$ and pyrimidine metabolism $(p<0.01)$. In addition, it induces oxidative stress $(p<0.01)$ shown by a decrease in total cell glutathione quantity and impacts cell energy through an increase in Krebs cycle intermediates (e.g., citrate, aconitate, fumarate) $(p<0.01)$ and a down-regulation of PCK-1 $(p<0.05)$ and FPB1 $(p<0.01)$, key enzymes in gluconeogenesis. Apart from glucose synthesis, gluconeogenesis is an important process in kidney mediated acid-base balance control. The observed variations found using this multi-omics approach clearly establish a dysregulation of energy production in epithelial cells of the renal tubule, and potentially of their functions, that can be implicated in tacrolimus chronic nephrotoxicity.

\section{Significance statement}

Tacrolimus is associated with nephrotoxicity for which the mechanism remains unclear. This study shows, using multi-omics approach, that tacrolimus induces oxidative stress, and dysregulated urea cycle, amino acid metabolism, pyrimidine metabolism, krebs cycle and glucose metabolism which may impact proximal tubular cells function and can be implicated in tacrolimus chronic nephrotoxicity. 


\section{Introduction}

Tacrolimus is a widely used immunosuppressive drug for preventing graft rejection after solid organ transplantation and treating autoimmune diseases (Brunet et al., 2019) . It has a narrow therapeutic range between $4-15 \mathrm{ng} / \mathrm{ml}$ in whole blood and is known to entail acute and chronic nephrotoxicity. Acute nephrotoxicity linked to high tacrolimus blood level (>20 ng/ml) is caused by hemodynamic perturbations and is reversible (Böttiger et al., 1999). In contrast, chronic nephrotoxicity is an irreversible decline of kidney function characterized by interstitial fibrosis and tubular atrophy, that could appear along time even in patients exposed to (low) pharmacological levels of tacrolimus.

The mechanism of tacrolimus nephrotoxicity is still not well understood. Many studies were conducted on proximal tubular cells and linked nephrotoxicity either to a mitochondrial toxicity characterized by functional and structural perturbation of the mitochondria (Lim, Shin, Luo, Quan, Cui, et al., 2019; Yu et al., 2019), or to increased oxidative stress caused by an increase of intracellular $\mathrm{H}_{2} \mathrm{O}_{2}$ levels or a decrease in MnSOD, an antioxidant enzyme (Lim et al., 2017; Zhou et al., 2004). Autophagy is also found to be disrupted in cells exposed to tacrolimus with an accumulation of autophagy vesicles in the cytoplasm (Lim, Shin, Luo, Quan, Ko, et al., 2019; Zheng et al., 2020). Furthermore, cells exposed to tacrolimus were also found to lose some transporter-related functions (Secker et al., 2019).

In this study, we employed a multi-omics screening of intracellular and extracellular contents of LLC-PK1 cells incubated with tacrolimus in order to understand its toxicity on the proximal tubule. We found that tacrolimus is able to induce the oxidative stress and to affect the urea cycle and energy metabolism, as suggested by increased concentrations of intermediates of the citric acid cycle and down-regulation of PCK-1 and FBP1, limiting enzymes in gluconeogenesis. In addition, tacrolimus was able to affect the metabolism of purine bases. 


\section{Materials and methods}

\section{Chemicals and reagents}

Dulbecco's Modified Eagle's Medium (DMEM)-Ham's F12 (1:1, 31331), Fetal Bovine Serum (10500), 1 M HEPES (15630), $7.5 \%$ Sodium bicarbonate (25080), 10,000 UI/mL Penicillin/ Streptomycin (15140), Dulbecco's Phosphate Buffer Saline (14190), Superscript II RT (180064022, Invitrogen $\left.{ }^{\mathrm{TM}}\right)$ and BCA protein assay KIT (23225, Pierce $\left.{ }^{\mathrm{TM}}\right)$ were purchased from ThermoFisher Scientific (Illkrich-Graffenstaden, France). Sodium selenite (S5261), insulin (14011), triiodothyronine (T6397) and dexamethasone (D4902), apo-transferrin human (T1147), desmopressin (V1005), tacrolimus (F4679), 2-isopropylmalic acid (333115), DTT (1.4-Dithiothritol) (D0632), Urea (U5378), lodoacetamide (I1149), AmiconUltra-0.5 centrifugal filter (UFC5010) DNase I Kit (AMPD1) were purchased from Sigma-Aldrich (St. Quentin Fallavier, France). NuleoSpin® RNA/Protein extraction kit (740933.50) was purchased from Macherey-Nagel (Hoerdt, France). Sequencing grade modified trypsin (V5111), RNasin® ribonuclease inhibitor (N2511), random primers (C118A) and MTS (G3581) were obtained from Promega (Courtaboeuf, France). QuantiFast ${ }^{\circledR}$ SYBER® Green PCR Kit (204054) was purchased from Qiagen. HLB oasis 3cc 60mg cartridges (WAT094226) were obtained from Water (saint Quentin en Yvelines, France).

\section{Cell culture condition}

LLC-PK1 (Lilly Laboratories Porcine Kidney-1) porcine proximal tubule cells (ATCC-CL-101, ATCC, Manassas, VA) were expanded in $75 \mathrm{~cm}^{2}$ flasks at $37{ }^{\circ} \mathrm{C}$ with $5 \% \mathrm{CO}_{2}$ and passed once confluence was reached. Culture medium consisted in a 1:1 DMEM-Ham's F12 mix supplemented with $5 \%$ FBS, 15 mM HEPES, $0.1 \%$ Sodium bicarbonate, $100 \mathrm{UI} / \mathrm{mL}$ Penicillin / Streptomycin and 50 nM Sodium selenite. LLC-PK1 cells were cultured between passage 7 and passage 20 .

LLC-PK1 were seeded in 6-well plates and expanded up to sub-confluence in the routine cell culture medium. Seeded LLC-PK1 sustained serum starvation and were fed with hormonally 
defined $(25 \mu \mathrm{g} / \mathrm{mL}$ insulin, $11 \mu \mathrm{g} / \mathrm{mL}$ transferrin, $50 \mu \mathrm{nM}$ triiodothyronine, $0.1 \mu \mathrm{M}$ dexamethasone, $0.1 \mu \mathrm{g} / \mathrm{mL}$ desmopressin) fresh medium to engage epithelial differentiation, for 24 hours. After differentiation, two treatment conditions were applied for $24 \mathrm{~h}$ i.e., i) ethanol $0.5 \%$ (control), or ii) tacrolimus $5 \mu \mathrm{M}$. For intracellular metabolomics investigations, 3 independent experiments were performed in triplicate, and 4 independent experiments were performed in triplicate for the extracellular metabolomics study, while for the proteomics study, 6 independent experiments were performed in singlicate.

\section{Viability test}

Cells were seeded in 96 -well plates at 25,000 cells/well for $24 \mathrm{~h}$, then differentiated for $24 \mathrm{~h}$ and treated with either $0.5 \%$ ethanol (control) or $5 \mu \mathrm{M}$ tacrolimus. Culture medium, with and without tacrolimus, was changed every $24 \mathrm{~h}$. Viability was assessed using the MTS test according to the manufacturer's instruction. Measurement of the absorbance was performed on PerkinElmer EnSpire® Multimode Plate Reader.

Viability was also assessed using flow cytometry. Briefly, cells were cultured in 6-well plates at 500,000 cells/well. After treatment, as described above, cells were washed twice with PBS and detached with trypsin EDTA. Cells were then washed twice with PBS and stained with annexin 5/7AAD. Reading was performed on a BD LSRFortessa ${ }^{\text {TM }}$ flow cytometer.

\section{Metabolomics study}

\section{Sample preparation}

Extraction of intracellular metabolites was based on a previously published method (Yuan et al., 2012). Treated and control cells were washed twice with ice cold PBS and then lysed using $3 \mathrm{ml}$ of a mixture of methanol/water $80 \% / 20 \%$ volume spiked with 2 -isopropylmalic acid at a final concentration of $500 \mathrm{nM}$ (internal standard) and incubated for 20 minutes at $-80^{\circ} \mathrm{C}$. Every well was then scrapped using cell scrapper, cell lysates transferred to $5 \mathrm{ml}$ Eppendorf tubes and centrifuged at $20,000 \mathrm{~g}$ for $5 \mathrm{~min}$ at $4^{\circ} \mathrm{C}$. One milliliter of each supernatant was then transferred into a $1.5 \mathrm{ml}$ Eppendorf tube and evaporated to dryness in a vacuum concentrator. 
The extract was then solubilized with $50 \mu \mathrm{L}$ of MiliQ water and transferred to a vial for mass spectrometry analysis.

Extracellular metabolites were extracted following manufacturer's instruction (Shimadzu). The culture medium of treated cells was collected and centrifuged at $3,000 \mathrm{~g}$ for 1 minute at room temperature to eliminate cell debris. Then, $100 \mu \mathrm{L}$ of the supernatant were added $200 \mu \mathrm{L}$ of

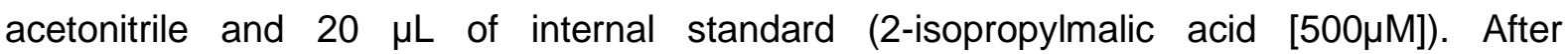
homogenization, samples were centrifuged at room temperature for 15 minutes at $15,000 \mathrm{~g}$. The supernatant therefore was then diluted $1 / 10$ in ultrapure water and transferred to a vial for mass spectrometry analysis.

\section{Metabolomics LC-MS/MS analysis}

Three $\mu \mathrm{L}$ of the suspended extracts were injected into the analytical system. Mass spectrometry analyses were performed using a LCMS-8060 (Shimadzu) tandem mass spectrometer and the LC-MS/MS "Method Package for Cell Culture Profiling Ver.2" (Shimadzu). The mass transitions of additional compounds were added after infusing the pure substances in the mass spectrometer. For each transition analyzed, only well-defined chromatographic peaks were considered. Area under the curve of every metabolite was normalized to the area under the curve of the internal standard (2-isopropylmalic acid).

\section{Data analysis and statistics}

In every experiment, treated samples were normalized by the corresponding control. MetaboAnalyst 5.0 computational platform (www.metaboanalyst.ca/faces/home.xhtml) was used for all statistical analyses. Univariable analysis was performed using the t-test; P-values were corrected for multiple testing using the False Discovery Rate (FDR) method. Multivariate exploration and unsupervised analysis by Principal Component Analyses (PCA) were performed. 


\section{Proteomics study}

\section{Sample preparation}

For intracellular proteomics, treated and control cells were washed twice with ice cold PBS and then extracted with the NucleoSpin ${ }^{\circledR}$ RNA/Protein extraction kit following manufacturer's instructions. The extracts were then stored at $-80^{\circ} \mathrm{C}$ until analysis.

For intracellular proteomics, protein content was estimated using the BCA protein assay following manufacturer's instruction. After that, $50 \mu \mathrm{g}$ of proteins were diluted in Q.S $200 \mu \mathrm{L}$ of $8 \mathrm{M}$ urea followed by $20 \mu \mathrm{L}$ of $50 \mathrm{mM}$ DDT and the samples were then incubated at $56^{\circ} \mathrm{C}$ for 20 minutes. Next, $20 \mu \mathrm{L}$ of $100 \mathrm{mM}$ iodoacetamide were added and the samples incubated in the dark for 20 minutes. The reduced samples were transferred to an Amicon ultracentrifugal filter and centrifuged at $14,000 \mathrm{~g}$ for 15 minutes. After the first centrifugation, the samples were washed twice by $8 \mathrm{M}$ urea and then twice with $25 \mathrm{mM}$ of ammonium bicarbonate. Digestion was performed inside the filter by adding $10 \mu \mathrm{L}$ of a solution of 0.1 $\mu \mathrm{g} / \mu \mathrm{L}$ of trypsin and the mixture was incubated for $3 \mathrm{~h}$ at $37^{\circ} \mathrm{C}$. Peptides were recovered by centrifuging the Amicon filter at $14,000 \mathrm{~g}$ for 15 minutes, then by washing it with $100 \mu \mathrm{L}$ of 1.5 $\mathrm{M} \mathrm{NaCl}$, then inverting it inside the tube and finally centrifuging at $1,000 \mathrm{~g}$ for 2 minutes. Solid Phase Extraction (SPE) of the peptides was performed using OASIS® HLB cartridges (Waters) preconditioned with $3 \mathrm{~mL}$ of methanol and $3 \mathrm{ml}$ of water/formic acid $0.5 \%$. After loading the diluted sample, a first wash was performed using $3 \mathrm{ml}$ of water/formic acid $0.5 \%$ and a second with water/methanol $5 \% /$ formic acid $0.5 \%$. The column was then dried for 15 minutes and the elution was achieved with $3 \mathrm{ml}$ of a mixture of acetonitrile/water $(70 / 30, \mathrm{v} / \mathrm{v})$. The eluate was then evaporated under nitrogen and the dry residue was dissolved in $100 \mu \mathrm{l}$ of water/acetonitrile/trifluoracetic acid (TFA) (98/2/0.05, v/v/v). The sample was then filtered on a spin filter $0.22 \mu \mathrm{m}$ (Agilent) and analyzed by mass spectrometry. 


\section{Proteomics MicroLC-MS/MS analysis}

The peptides resulting from protein digestion were analysed by microLC-MS/MS using a nanoLC 425 liquid chromatography system in the micro-flow mode (Eksigent, Dublin, CA), coupled to a quadrupole-time-of-flight tandem mass spectrometer (TripleTOF 5600+, Sciex, Framingham, MA) operated in the high-sensitivity mode. Reverse-phase LC was performed in a trap-and-elute configuration using a trap column (C18 Pepmap100 cartridge, $300 \mu \mathrm{m}$ i.d. x $5 \mathrm{~mm}, 5 \mu \mathrm{m}$; Thermo Scientific) and a C18 analytical column (ChromXP, $150 \times 0.3 \mathrm{~mm}$ i.d., $120 \AA$, $3 \mu \mathrm{m} ; \quad$ Sciex) with the following mobile phases: loading solvent (water/acetonitrile/trifluoroacetic acid 98/2/0.05 (v/v)), solvent $A(0.1 \%(\mathrm{v} / \mathrm{v})$ formic acid in water) and solvent B (water/acetonitrile/formic acid 5/95/0.1\% (v/v)). All samples were loaded, trapped and desalted using a loading solvent flowrate of $10 \mu \mathrm{L} / \mathrm{min}$ for 5 minutes. Chromatographic separation was performed at a flow rate of $3 \mu \mathrm{L} / \mathrm{min}$ as follows: initial, $5 \%$ $\mathrm{B}$, increased to $25 \%$ in $145 \mathrm{~min}$, then to $95 \% \mathrm{~B}$ in $10 \mathrm{~min}$, maintained at $95 \%$ for $15 \mathrm{~min}$, and finally, decreased to $5 \% \mathrm{~B}$ for re-equilibration.

One $\mu \mathrm{g}$ of each sample (equivalent protein content) was first subjected to data-dependent acquisition (DDA) to generate the SWATH-MS spectral library. MS and MS/MS data were continuously recorded with up to 30 precursors selected for fragmentation from each MS survey scan. Precursor selection was based upon ion intensity, whether or not the precursor had been previously selected for fragmentation (dynamic exclusion). Ions were fragmented using rolling collision energy. All DDA mass spectrometer files were searched using ProteinPilot software v.5.0.1 (Sciex) and the Paragon algorithm. Data were analyzed with the following parameters: cysteine alkylation with iodoacetamide, digestion by trypsin and no special factors. The search was conducted using a rapid identification effort of a UniProt database (June 2018 release) containing non-redundant proteins of Sus scrofa. The output of this search was used as the reference spectral library.

For sample analysis, the equivalent of $1 \mu \mathrm{g}$ protein content was injected in the analytical system and subjected to data-independent acquisition (DIA) using 60 variable swath 
windows over the $400-1250 \mathrm{~m} / \mathrm{z}$ range. For these experiments, the mass spectrometer was operated in such a way that a 50-ms survey scan (TOF-MS) was acquired and subsequent MS/MS experiments were performed on all precursors using an accumulation time of $120 \mathrm{~ms}$ per swath window for a total cycle time of $7.3 \mathrm{~s}$. Parent ions were fragmented using rolling collision energy corresponding to the $\mathrm{m} / \mathrm{z}$ range window. DIA samples were processed using PeakView v.2.1 (Sciex) with SWATH v.2.0 module and the reference spectral library generated above. Spectral alignment and targeted data extraction were performed using an extraction window of $15 \mathrm{~min}$ and the following parameters: protein identity confidence $>99 \%$ with maximum of 10 peptides per protein and 5 fragments per peptide with 10 ppm error tolerance. Shared and modified peptides were excluded.

\section{Data analysis and statistics}

Statistical analysis of proteomics data analyses was performed using R. First of all, each batch of treated and control cells was normalized classically (center and scale). Second, delta values were computed from normalized data.

For each protein i, Delta $_{i}=\ln \left(\frac{\text { treated }_{i}}{\text { control }_{i}}\right)$

Third, proteins with delta $<\ln (0.8)$ or $>-\ln (0.8)$, reflecting a decrease and increase of $20 \%$ of protein expression respectively and identified using more than 2 peptides, were considered as differentially expressed.

\section{RT-qPCR}

RNA and proteins (used for the proteomic study) were extracted using the NucleoSpin ${ }^{\circledR}$ RNA/Protein extraction kit (Macherey-Nagel). RNA quantification was performed using a Nanodrop® spectrophotometer (ND-1000). To eliminate residual DNA, samples were treated with DNase I Kit (sigma AMPD1). One $\mu \mathrm{g}$ of RNA was then reverse-transcribed into complementary DNA (cDNA) using Superscript II RT, random primers and RNasin® ribonuclease inhibitor (Promega N2511). All these steps were carried out following the manufacturer's instructions. For qPCR reaction, a mix was prepared for each sample 
containing $40 \mathrm{ng}$ of $\mathrm{cDNA}, 2 \mu \mathrm{L}$ of a mix of forward and reverse primers (final concentration for every primer: $400 \mathrm{nM}$ ), $12.5 \mu \mathrm{L}$ of QuantiFast ${ }^{\circledR}$ SYBER ${ }^{\circledR}$ Green PCR Kit and q.s. $25 \mu \mathrm{L}$ RNAse-free water. The reaction was performed on a Rotor Gene Q (Qiagen) using the following program: 5 minutes at $95^{\circ} \mathrm{C}$ followed by 45 cycle of $10 \mathrm{~s}$ at $95^{\circ} \mathrm{C}, 30 \mathrm{~s}$ at $60^{\circ} \mathrm{C}$. Acquisition was done in green. Fold-change was calculated $\left(2^{-\Delta \Delta C t}\right)$ and statistical analysis was performed using paired t-test using Prism 5.0 software. Complete list of used primers is presented in Supplemental table 1.

\section{Results}

Cell viability was not affected after $24 \mathrm{~h}$ and $48 \mathrm{~h}$ of treatment with $5 \mu \mathrm{M}$ of tacrolimus. At $72 \mathrm{~h}$, the MTS test showed a significant decrease of $5 \%(p=0.0003)$ in cell viability while flow cytometry analysis did not show any difference (Figure 1).

\section{Intracellular metabolomics}

Seventy-nine metabolites were detected by LC-MS/MS and heat-map analysis clearly discriminated the two conditions (controls or tacrolimus) (Supplemental table 2) (Figure2). Principal component analysis neatly separated them into the two experimental conditions, controls or tacrolimus treated cells, $47.6 \%$ of the variation being explained by the first component and $21.8 \%$ by the second (Figure 2 ).

Univariate analysis (t-test) showed that 20 of these metabolites were significantly increased and 15 significantly decreased ( $p$-value $<0.05$ and FDR<0.05) (Table 1 ). Most of these metabolites were amino acids, citric acid cycle intermediates, urea cycle intermediates and antioxidant reaction intermediates.

Enrichment pathway analysis of these 35 metabolites confirmed that tacrolimus induces changes in the urea cycle, in the amino acid metabolism, in the citric acid cycle, and in glutathione metabolism (Figure 3). 


\section{Extracellular metabolomics}

Fifty-nine metabolites were detected by LC-MS/MS analysis and, as for intracellular metabolites, heat-map analysis clearly discriminated the two conditions (controls or tacrolimus) (Supplemental table 3) (Figure 4). PCA also separated them neatly by means of the first two principal components, $30.3 \%$ of the variation being explained by the first and $16.5 \%$ by the second (Figure 4$)$.

Out of the 59 metabolites detected in the extracellular medium, 17 were found to be significantly modified ( $p$-value $<0.05$ and FDR $<0.05$ ) by tacrolimus exposure including amino acids, citric acid cycle intermediates and purine and pyrimidine bases (Figure 4 and Table 2). Enrichment pathway analysis confirmed that the pathways significantly impacted are those of the urea cycle, amino acid metabolism, pyrimidine and glutathione metabolism (Figure 5).

\section{Intracellular proteomics}

A total of 846 proteins were identified and quantified over the 6 replicates (Supplemental table 4). Only proteins identified using more than 2 peptides were retained. Eleven proteins were found to be differentially expressed and all of them were down-regulated (Figure 6).

Two of them are involved in anabolic processes (gluconeogenesis: Phosphoenolpyruvate carboxykinase "A5GFS4", Fatty acid synthesis: fatty acid synthase "I3LCW1"), and two others are subunits of the complex 1 involved in the mitochondrial membrane respiratory chain (NADH dehydrogenase [ubiquinone] 1 alpha subcomplex subunit 5 "A0A287BAW0", NADH dehydrogenase [ubiquinone] flavoprotein 2 "F1SM98"). In our study we will focus on PCK-1.

\section{Intracellular transcriptomics}

Downregulation of PCK-1 mRNA was confirmed by RT-qPCR $(p=0.0329)$. FBP1, a limiting enzyme in gluconeogenesis was also significantly downregulated $(p=0.0031)$, while the decrease of FBP2, the other limiting enzyme in gluconeogenesis, was not significant (Figure 7). 


\section{Discussion}

This study of the effects of tacrolimus on a porcine cell line suggests that tacrolimus increases the oxidative stress, perturbs the cell energy metabolism and downregulate gluconeogenesis in proximal tubular cells.

As summarized in figure 8 , the intracellular metabolomics study clearly showed increased oxidative stress through a decrease of the total content of intracellular glutathione (including glutathione, oxidized glutathione and Y-glutamyl-cysteine) in tacrolimus treated cells. In addition, the lower level of cystine found in the culture medium of tacrolimus treated cells (Figure 4A, Table 2) suggests an increased uptake of this important source of cysteine for glutathione synthesis. Furthermore, intracellular metabolomics show increased folate consumption (Table.1), which can be closely related to the oxidative stress. In fact, folic acid is known to be a free radical scavenger. Additionally, folate metabolism is a major source of $\mathrm{NADPH}$, a cofactor of glutathione reductase in charge of the regeneration of glutathione from oxidized glutathione (Fan et al., 2014). These results are consistent with other studies demonstrating that tacrolimus toxicity is mediated by an oxidative stress (Lim, Shin, Luo, Quan, Cui, et al., 2019; Zhou et al., 2004) and it validates our experimental setting.

Besides oxidative stress induction, tacrolimus altered the citric acid cycle, as clearly shown by intracellular increase of different citric acid cycle intermediates (Table 1, Figure 3 and Figure 8). This increase can be caused by an accumulation of the metabolites or an increase of the citric acid cycle flux. This can be linked to different intracellular events, found in our analysis, that occur simultaneously such as the oxidative stress, the down-regulation of PCK-1.

As for folic acid metabolism, the citric acid cycle is a major source of NADPH, which is generated by isocitrate dehydrogenase and malic enzyme and is essential to reduce oxidative stress. In this case, the increase of the citric acid cycle intermediates may be considered as a response to the oxidative stress. It may suggest increased glycolysis which is also essential to produce NADPH. Unfortunately, our method did not target any glycolysis intermediate that 
may have helped us to confirm this hypothesis or not. In contrast, oxidative stress can reduce the activity of some citric acid enzymes like aconitase, oxoglutarate dehydrogenase and succinic dehydrogenase that may also result in citric acid cycle intermediate accumulation (Tretter \& Adam-Vizi, 2005). In addition, the stress of the endoplasmic reticulum, which may be implicated in tacrolimus nephrotoxicity, can increase the citric acid cycle flux mediated by the redox metabolites (Gansemer et al., 2020). Lactic acid was also decreased in the intracellular space and was less excreted to the culture medium (Table 2), which is in favor or an impaired citric acid flux. Monitoring citric acid cycle intermediates during tacrolimus treatment using labelled citric acid could help to determine whether tacrolimus causes an accumulation of the metabolites or an increase of the citric acid cycle flux (Lorkiewicz et al., 2019).

Proteomics analysis showed differently expressed proteins with PCK-1 being the major down regulated protein (Figure 6). PCK-1 is a limiting enzyme in the process of gluconeogenesis that converts oxaloacetate to phosphoenolpyruvate. A decrease in the activity of this enzyme may cause an accumulation of citric acid intermediate metabolites by limiting the transformation of oxaloacetate. In fact, PKC-1 -/- mice showed a tenfold increase in malate level in the liver as compared to controls (Hakimi et al., 2005). In addition, a study performed on a hepatic cell line and in mice showed that tacrolimus decreased the hepatic expression of PCK-1 (Ling et al., 2020). This effect was also seen in a primary culture of human $\beta$-pancreatic cells exposed to tacrolimus (Kolic et al., 2020). At the kidney level, a study conducted in rats treated with tacrolimus found a downregulation of PCK-1 mRNA (Morris et al., 1991). Given the difficulties encountered to find antibodies against porcine proteins, we chose to strengthen our proteomics results by measuring the expression of the corresponding mRNAs. RT-qPCR showed that PCK-1 mRNA was down-regulated when cells were exposed to tacrolimus (Figure 7), in line with the above-mentioned studies, thus validating our proteomics findings.

In order to investigate if tacrolimus affects only PCK-1 or if it has an impact on the whole gluconeogenesis process, mRNA expression of FBP1 and FBP2, two other limiting enzymes 
in the gluconeogenesis process, was investigated showing that tacrolimus significantly downregulates FBP1, and maybe also FBP2 although it did not reach statistical significance (Figure 7). This suggests that tacrolimus impacts the whole gluconeogenesis process and reduces glucose synthesis. This may appear as contradictory with the fact that tacrolimus induces diabetes in patients. In fact, tacrolimus diabetogenic effect is probably mediated by its impact on insulin secretion and activity and not on glucose catabolism. In addition, a study conducted in mice treated with tacrolimus showed decreased glycemia after $16 \mathrm{~h}$ of fasting as compared to controls, confirming that tacrolimus affects gluconeogenesis (Ling et al., 2020). All these findings and arguments converge to highlight the effect of tacrolimus on gluconeogenesis. Kidneys have gluconeogenesis capacity and play a role in glucose homeostasis, which may have a systemic impact on patients treated with tacrolimus, but more than this, glucose metabolism deregulation in tubular cells, as suggested by down regulation of PCK-1, FBP1 and possibly FBP2, may play a role in tacrolimus nephrotoxicity. In addition, PCK-1 downregulation can impact the acid-base balance. PCK-1 was upregulated in proximal tubular cells in case of acidosis and increased the transformation of oxaloacetate to phosphoenolpyruvate and $\mathrm{HCO}_{3}$-(Alleyne \& Scullard, 1969; Curthoys \& Gstraunthaler, 2001). The latter is released in the blood stream to regulate the acid-base disorder. In addition, tacrolimus lowered the capacity to regulate induced metabolic acidosis in a murine model (Mohebbi et al., 2009). This was partially explained by some alteration of renal acid-base transport proteins. PCK-1 downregulation by tacrolimus can be a complementary explanation to this impaired response to metabolic acidosis. Furthermore, PCK-1 is upregulated during intracellular acidosis induced by hypokalemia in vitro (Gstraunthaler et al., 2000). Downregulation of PCK-1 can impact intracellular $\mathrm{pH}$ regulation and induce direct toxicity on proximal tubular cells.

Metabolites of the urea cycle were differently impacted by tacrolimus (Figure 8). Aspartate, arginosuccinate and fumarate levels were increased in treated cells, while the levels of arginine and two of its products in the cycle, citrulline and ornithine, were decreased. On top 
of the intracellular variations, cells treated with tacrolimus increased their consumption of extracellular citrulline and released less ornithine. These results strongly suggest that the urea cycle activity is increased by tacrolimus, which may be linked through fumarate with the increased citric acid cycle flux. In addition, intracellular putrescine, a product of ornithine, increases while its excretion in the extracellular media decreases. This suggests a perturbation of the transporter-dependent secretion of putrescine that accumulates in the intracellular space, or an increase of its synthesis from ornithine. The accumulation of putrescine can lead to cytotoxicity (Tome et al., 1997; Xie et al., 1997).

L-carnitine is an essential metabolite for lipid metabolism. It acts by transporting lipids from the extra- to the intra-mitochondrial space. It is also responsible for the balance between free and esterified CoA, formed by the degradation of Acetyl Co-A (Stephens et al., 2007). In consequence, it can be found in free and bound forms. The increased level of L-carnitine in tacrolimus treated cells can be caused by an upregulation of its synthesis as a response to the increased citric acid cycle flux so as to transport fatty acids into the mitochondria. However, this can be also explained by an increase of its free form caused by a deficiency in carnitine acylation. In both cases, this variation is linked to a perturbation in the intracellular energy metabolism.

All of the metabolomic and proteomic variations described above support deregulations of the energy metabolism induced by tacrolimus in tubular proximal cells. These cells, in respect to their functions involving a large number of energy-dependent transports, can be largely impacted by perturbations of energy metabolisms, which may be root mechanisms in the tubular toxicity of tacrolimus. In addition, PCK-1 downregulation can have an impact beyond the energy metabolism and may affect specific tubular functions such as glycemia regulation and acid-base balance.

It is worth mentioning that the tacrolimus concentration used in this study was much higher than trough tacrolimus blood concentration found in treated patients (typically 4-15 $\mathrm{ng} / \mathrm{ml}$ ). However, the concentration used $(5 \mu \mathrm{M})$, did not show any cytotoxic effect after $24 \mathrm{~h}$ incubation 
and it is at the lower end of the concentrations reported in the literature when investigating tacrolimus nephrotoxicity in vitro, which can be up to $74 \mu \mathrm{M}$ (Bennett et al., 2016; GonzálezGuerrero et al., 2013; Lim et al., 2017; Lim, Shin, Luo, Quan, Cui, et al., 2019; Lim, Shin, Luo, Quan, Ko, et al., 2019; Yu et al., 2019; Zhou et al., 2004). Even toxicity findings made at this relatively high concentrations could be validated in animal models of chronic tacrolimus nephrotoxicity (Lim, Shin, Luo, Quan, Ko, et al., 2019; Yu et al., 2019). This suggests that our results, obtained at intermediate concentrations, may raise pertinent hypotheses regarding tacrolimus toxicity pathways. Because tacrolimus nephrotoxicity (apart from its vasoconstrictive properties) is a delayed and chronic process, its in vitro exploration would require either a very long incubation time, which is hardly feasible, or higher concentrations of tacrolimus, which we chose, still avoiding cytotoxic concentrations. There is no example in the literature we know of that employed a different strategy.

Finally, it is worth mentioning that the variations reported here were observed at $24 \mathrm{~h}$ incubation and that a more detailed kinetics (more time points) might allow better understanding of tacrolimus underlying mechanisms.

\section{Conclusion}

This multi-omics study on a proximal tubular cell line shows that acute tacrolimus exposure induces modifications in the energy and glucose metabolism, an increase of the oxidative stress, a perturbation of different metabolic pathways and possibly of gluconeogenesis that impact glycemia regulation and intra-extracellular acid-base balance. These short-term modifications might be implicated in tacrolimus chronic nephrotoxicity. 


\section{Acknowledgments}

The authors thank Jean-Sebastien Bernard for helping with experiments performing.

Authorship Contributions:

Participated in research design: Hassan Aouad, Quentin Faucher, Pierre Marquet, Marie Essig.

Conducted the experiments: Hassan Aouad.

Contributed to the experiments: Hassan Aouad, François-Ludovic Sauvage, Emilie Pinault, Hélène Arnion.

Performed data analysis: Hassan Aouad, Quentin Faucher, Claire-Cécile Barrot.

Wrote or contributed to the writing of the manuscript: Hassan Aouad, Pierre Marquet, Marie Essig, François-Ludovic Sauvage, Emilie Pinault, Quentin Faucher, Claire-Cécile Barrot, Hélène Arnion. 


\section{References}

Alleyne, G. A., \& Scullard, G. H. (1969). Renal metabolic response to acid base changes. I. Enzymatic control of ammoniagenesis in the rat. The Journal of Clinical Investigation, 48(2), 364-370. https://doi.org/10.1172/JCl105993

Bennett, J., Cassidy, H., Slattery, C., Ryan, M. P., \& McMorrow, T. (2016). Tacrolimus Modulates TGF$\beta$ Signaling to Induce Epithelial-Mesenchymal Transition in Human Renal Proximal Tubule Epithelial Cells. Journal of Clinical Medicine, 5(5), 50. https://doi.org/10.3390/jcm5050050

Böttiger, Brattström, Tydén, Säwe, \& Groth. (1999). Tacrolimus whole blood concentrations correlate closely to side-effects in renal transplant recipients. British Journal of Clinical Pharmacology, 48(3), 445-448. https://doi.org/10.1046/j.1365-2125.1999.00007.x

Brunet, M., van Gelder, T., Åsberg, A., Haufroid, V., Hesselink, D. A., Langman, L., Lemaitre, F., Marquet, P., Seger, C., Shipkova, M., Vinks, A., Wallemacq, P., Wieland, E., Woillard, J. B., Barten, M. J., Budde, K., Colom, H., Dieterlen, M.-T., Elens, L., ... Bergan, S. (2019). Therapeutic Drug Monitoring of Tacrolimus-Personalized Therapy: Second Consensus Report. Therapeutic Drug Monitoring, 41(3), 261-307. https://doi.org/10.1097/FTD.0000000000000640

Curthoys, N. P., \& Gstraunthaler, G. (2001). Mechanism of increased renal gene expression during metabolic acidosis. American Journal of Physiology. Renal Physiology, 281(3), F381-390. https://doi.org/10.1152/ajprenal.2001.281.3.F381

Fan, J., Ye, J., Kamphorst, J. J., Shlomi, T., Thompson, C. B., \& Rabinowitz, J. D. (2014). Quantitative flux analysis reveals folate-dependent NADPH production. Nature, 510(7504), 298-302. https://doi.org/10.1038/nature13236

Gansemer, E. R., McCommis, K. S., Martino, M., King-McAlpin, A. Q., Potthoff, M. J., Finck, B. N., Taylor, E. B., \& Rutkowski, D. T. (2020). NADPH and Glutathione Redox Link TCA Cycle Activity to Endoplasmic Reticulum Homeostasis. IScience, 23(5), 101116.

https://doi.org/10.1016/j.isci.2020.101116 
González-Guerrero, C., Ocaña-Salceda, C., Berzal, S., Carrasco, S., Fernández-Fernández, B., CannataOrtiz, P., Egido, J., Ortiz, A., \& Ramos, A. M. (2013). Calcineurin inhibitors recruit protein kinases JAK2 and JNK, TLR signaling and the UPR to activate NF-KB-mediated inflammatory responses in kidney tubular cells. Toxicology and Applied Pharmacology, 272(3), 825-841. https://doi.org/10.1016/j.taap.2013.08.011

Gstraunthaler, G., Holcomb, T., Feifel, E., Liu, W., Spitaler, N., \& Curthoys, N. P. (2000). Differential expression and acid-base regulation of glutaminase mRNAs in gluconeogenic LLC-PK1FBPase+ cells. American Journal of Physiology-Renal Physiology, 278(2), F227-F237. https://doi.org/10.1152/ajprenal.2000.278.2.F227

Hakimi, P., Johnson, M. T., Yang, J., Lepage, D. F., Conlon, R. A., Kalhan, S. C., Reshef, L., Tilghman, S. M., \& Hanson, R. W. (2005). Phosphoenolpyruvate carboxykinase and the critical role of cataplerosis in the control of hepatic metabolism. Nutrition \& Metabolism, 2, 33. https://doi.org/10.1186/1743-7075-2-33

Kolic, J., Beet, L., Overby, P., Cen, H. H., Panzhinskiy, E., Ure, D. R., Cross, J. L., Huizinga, R. B., \& Johnson, J. D. (2020). Differential Effects of Voclosporin and Tacrolimus on Insulin Secretion From Human Islets. Endocrinology, 161(bqaa162). https://doi.org/10.1210/endocr/bqaa162 Lim, S. W., Jin, L., Luo, K., Jin, J., Shin, Y. J., Hong, S. Y., \& Yang, C. W. (2017). Klotho enhances FoxO3mediated manganese superoxide dismutase expression by negatively regulating PI3K/AKT pathway during tacrolimus-induced oxidative stress. Cell Death \& Disease, 8(8), e2972. https://doi.org/10.1038/cddis.2017.365

Lim, S. W., Shin, Y. J., Luo, K., Quan, Y., Cui, S., Ko, E. J., Chung, B. H., \& Yang, C. W. (2019). Ginseng increases Klotho expression by FoxO3-mediated manganese superoxide dismutase in a mouse model of tacrolimus-induced renal injury. Aging, 11(15), 5548-5569. https://doi.org/10.18632/aging.102137 
Lim, S. W., Shin, Y. J., Luo, K., Quan, Y., Ko, E. J., Chung, B. H., \& Yang, C. W. (2019). Effect of Klotho on autophagy clearance in tacrolimus-induced renal injury. The FASEB Journal, 33(2), 26942706. https://doi.org/10.1096/fj.201800751R

Ling, Q., Huang, H., Han, Y., Zhang, C., Zhang, X., Chen, K., Wu, L., Tang, R., Zheng, Z., Zheng, S., Li, L., \& Wang, B. (2020). The tacrolimus-induced glucose homeostasis imbalance in terms of the liver: From bench to bedside. American Journal of Transplantation, 20(3), 701-713. https://doi.org/10.1111/ajt.15665

Lorkiewicz, P. K., Gibb, A. A., Rood, B. R., He, L., Zheng, Y., Clem, B. F., Zhang, X., \& Hill, B. G. (2019). Integration of flux measurements and pharmacological controls to optimize stable isotoperesolved metabolomics workflows and interpretation. Scientific Reports, 9(1), 13705. https://doi.org/10.1038/s41598-019-50183-3

Mohebbi, N., Mihailova, M., \& Wagner, C. A. (2009). The calcineurin inhibitor FK506 (tacrolimus) is associated with transient metabolic acidosis and altered expression of renal acid-base transport proteins. American Journal of Physiology-Renal Physiology, 297(2), F499-F509. https://doi.org/10.1152/ajprenal.90489.2008

Morris, S. M., Kepka-Lenhart, D., Curthoys, N. P., McGill, R. L., Marcus, R. J., \& Adler, S. (1991). Disruption of renal function and gene expression by FK 506 and cyclosporine. Transplantation Proceedings, 23(6), 3116-3118.

Secker, P. F., Schlichenmaier, N., Beilmann, M., Deschl, U., \& Dietrich, D. R. (2019). Functional transepithelial transport measurements to detect nephrotoxicity in vitro using the RPTEC/TERT1 cell line. Archives of Toxicology, 93(7), 1965-1978. https://doi.org/10.1007/s00204-019-02469-8

Stephens, F. B., Constantin-Teodosiu, D., \& Greenhaff, P. L. (2007). New insights concerning the role of carnitine in the regulation of fuel metabolism in skeletal muscle. The Journal of Physiology, 581(2), 431-444. https://doi.org/10.1113/jphysiol.2006.125799 
TOME, E. M., FISER, M. S., PAYNE, M. C., \& GERNER, W. E. (1997). Excess putrescine accumulation inhibits the formation of modified eukaryotic initiation factor $5 \mathrm{~A}$ (elF-5A) and induces apoptosis. Biochemical Journal, 328(3), 847-854. https://doi.org/10.1042/bj3280847

Tretter, L., \& Adam-Vizi, V. (2005). Alpha-ketoglutarate dehydrogenase: A target and generator of oxidative stress. Philosophical Transactions of the Royal Society B: Biological Sciences, 360(1464), 2335-2345. https://doi.org/10.1098/rstb.2005.1764

Xie, X., Tome, M. E., \& Gerner, E. W. (1997). Loss of Intracellular Putrescine Pool-Size Regulation Induces Apoptosis. Experimental Cell Research, 230(2), 386-392. https://doi.org/10.1006/excr.1996.3442

Yu, J. H., Lim, S. W., Luo, K., Cui, S., Quan, Y., Shin, Y. J., Lee, K. E., Kim, H. L., Ko, E. J., Chung, B. H., Kim, J. H., Chung, S. J., \& Yang, C. W. (2019). Coenzyme Q10 alleviates tacrolimus-induced mitochondrial dysfunction in kidney. The FASEB Journal, 33(11), 12288-12298. https://doi.org/10.1096/fj.201900386RR

Yuan, M., Breitkopf, S. B., Yang, X., \& Asara, J. M. (2012). A positive/negative ion-switching, targeted mass spectrometry-based metabolomics platform for bodily fluids, cells, and fresh and fixed tissue. Nature Protocols, 7(5), 872-881. https://doi.org/10.1038/nprot.2012.024

Zheng, H., Zhang, H., Zhu, C., Li, H., Cui, S., Jin, J., Piao, S., Jiang, Y., Xuan, M., Jin, J., Jin, Y., Lee, J., Chung, B., Choi, B., Yang, C., \& Li, C. (2020). L -C arnitine protects against tacrolimus-induced renal injury by attenuating programmed cell death via PI3K/AKT/PTEN signaling. Acta Pharmacologica Sinica, 1-11. https://doi.org/10.1038/s41401-020-0449-8

Zhou, X., Yang, G., Davis, C. A., Doi, S. Q., Hirszel, P., Wingo, C. S., \& Agarwal, A. (2004). Hydrogen peroxide mediates FK506-induced cytotoxicity in renal cells. Kidney International, 65(1), 139-147. https://doi.org/10.1111/j.1523-1755.2004.00380.x 


\section{Footnotes}

This work received no external funding.

Reprint requests should be sent to Prof. Pierre Marquet, Service de Pharmacologie,

Toxicologie et Pharmacovigilance, Centre Hospitalier Universitaire, 2 rue Martin Luther King,

87042 Limoges, France.

Email: pierre.marquet@unilim.fr 


\section{Figure legends}

Figure 1: LLC-PK1 viability after incubation with $0.5 \%$ ethanol (control $(\mathrm{C})$ ) or $5 \mu \mathrm{M}$ of tacrolimus (TAC) for $24 \mathrm{~h}, 48 \mathrm{~h}$ and $72 \mathrm{~h}$, assessed using the MTS viability assay $(\mathrm{n}=18$, left graph) and annexin 5/ 7AAD staining ( $n=5$, right graph). Graphs represent the $\%$ of cell viability with tacrolimus as compared to control for each incubation duration. Statistical analysis with the t-test. ${ }^{* * *} p<0.001$.

Figure 2: Multivariate exploration of intracellular metabolites variations after $24 \mathrm{~h}$ tacrolimus exposure $(n=9)$. A. Heatmap clustering distinguishing the control condition (C) from tacrolimus treated cells $(\mathrm{T})$, based on all metabolites detected by LC-MS/MS. B. PCA scores plot showing complete separation between groups 0 and 1 with principal components PC1 describing $47.6 \%$ of the variation and $\mathrm{PC} 2,21.8 \%$ ( 0 (red circles): $0.5 \%$ ethanol (control); 1 (green circles): tacrolimus $5 \mu \mathrm{M})$.

Figure 3: Dot plot of pathway enrichment analysis based on the intracellular concentrations of metabolites significantly modified in tacrolimus treated cells as compared to control (Table 1).

Figure 4: Multivariate exploration of extracellular metabolites variations after $24 \mathrm{~h}$ exposure to tacrolimus ( $\mathrm{n}=12)$. A. Heatmap clustering distinguishing control condition (C) and tacrolimus treated cells $(\mathrm{T})$, based on all metabolites detected by LC-MS/MS analysis. B. PCA scores plot showing complete separation between groups 0 and 1 with principal component PC1 describing $30.3 \%$ of the variation and PC2, $16.5 \%$ ( 0 (red circles): $0.5 \%$ ethanol (control); 1 (green circles): tacrolimus $5 \mu \mathrm{M}$ for $24 \mathrm{~h})$.

Figure 5: Dot plot of pathway enrichment analysis based on extracellular concentrations of metabolites significantly modified in tacrolimus treated cells as compared to controls (Table 2). 
Figure 6: Intracellular concentrations of proteins modified after $24 \mathrm{~h}$ exposure to $5 \mu \mathrm{M}$ of tacrolimus, as determined by SWATH proteomics analysis ( $n=6$ independent experiments). Proteins with a mean delta $>\ln (0.8)$ or $<-\ln (0.8)$ were considered to be differentially expressed.

Figure 7: Effect of tacrolimus exposure on the mRNA levels of PCK-1, FBP1 and FBP2 in proximal tubular cells. Fold-change of PCK-1, FBP1 and FBP2 mRNAs in cells exposed to tacrolimus $5 \mu \mathrm{M}(\mathrm{TAC})$ with respect to the control $(\mathrm{C}$, exposed to $0.5 \%$ ethanol). Targeted gene mRNA signals were normalized to the signal of GAPDH mRNA used as housekeeping gene. ${ }^{*} \mathrm{p}<0.05 ;{ }^{* *} \mathrm{p}<0.01$ by student $t$-test ( $\mathrm{n}=6$ independent experiments).

Figure 8: Main metabolomic pathways modulated by tacrolimus. Metabolites in the intracellular (name) and extracellular (marked with \#) spaces are presented. Decreased metabolites are colored in green, increased metabolites in red, metabolites normally expressed in black and those not detected in blue. Purple arrows show cycle directions. 


\section{Tables}

Table 1. Fold-change of Intracellular metabolites significantly modified by tacrolimus exposure $(n=9)(p-$ value $<0.05)$

\begin{tabular}{|c|c|c|c|}
\hline Metabolite & Fold-change & P-value (T-test) & FDR \\
\hline L-Carnitine & 1.7425 & $8.9464 \mathrm{e}-11$ & $7.0677 \mathrm{e}-09$ \\
\hline Malic acid & 1.4603 & $2.2221 \mathrm{e}-10$ & $8.7772 \mathrm{e}-09$ \\
\hline Fumaric acid & 1.383 & $3.5883 \mathrm{e}-10$ & $9.4491 e-09$ \\
\hline Aconitate & 1.4654 & $7.0907 e-08$ & $1.235 \mathrm{e}-06$ \\
\hline 2-aminobutyric acid & 1.2619 & $7.8167 e-08$ & $1.235 \mathrm{e}-06$ \\
\hline Glutathione & 0.26167 & $1.526 \mathrm{e}-07$ & $2.0093 e-06$ \\
\hline Citric acid & 1.4012 & $1.8841 \mathrm{e}-07$ & $2.1264 \mathrm{e}-06$ \\
\hline Argininosuccinic acid & 1.4044 & $8.0989 \mathrm{e}-07$ & $7.9976 \mathrm{e}-06$ \\
\hline Y-Glutamylcysteine & 0.38874 & $2.4983 e-06$ & $2.193 e-05$ \\
\hline N-Acetylaspartic acid & 1.4012 & $5.9313 e-06$ & $4.6858 \mathrm{e}-05$ \\
\hline Succinic acid & 1.2442 & $9.4702 \mathrm{e}-06$ & $6.8013 e-05$ \\
\hline Oxidized glutathione & 0.53446 & $1.206 \mathrm{e}-05$ & $7.9393 e-05$ \\
\hline S-adenosylhomocysteine & 0.67941 & $2.2869 \mathrm{e}-05$ & 0.00013898 \\
\hline Valine & 0.78981 & 0.0001452 & 0.00081935 \\
\hline Isoleucine & 0.8245 & 0.00018176 & 0.00095725 \\
\hline Aspartic acid & 1.2697 & 0.00044392 & 0.0021918 \\
\hline Threonic acid & 1.3235 & 0.00055436 & 0.0025761 \\
\hline Ornithine & 0.80762 & 0.00067636 & 0.0029685 \\
\hline Oxoglutaric acid & 1.2475 & 0.0008545 & 0.0035529 \\
\hline Pantothenic acid & 1.0773 & 0.00099844 & 0.0037844 \\
\hline Choline & 0.88625 & 0.001006 & 0.0037844 \\
\hline Leucine & 0.85471 & 0.00139 & 0.0049616 \\
\hline Glycine & 1.1806 & 0.0014445 & 0.0049616 \\
\hline Lactic acid & 0.95114 & 0.001715 & 0.0056453 \\
\hline D gluconic acid sodium salt & 1.1862 & 0.001793 & 0.005666 \\
\hline Phenylalanine & 0.89058 & 0.0025434 & 0.0077046 \\
\hline Putrescine & 1.2476 & 0.0026332 & 0.0077046 \\
\hline
\end{tabular}


bioRxiv preprint doi: https://doi.org/10.1101/2021.07.29.454229; this version posted July 30, 2021. The copyright holder for this preprint (which was not certified by peer review) is the author/funder. All rights reserved. No reuse allowed without permission.

\begin{tabular}{|l|l|l|l|}
\hline Glutamine & 1.3081 & 0.0042679 & 0.012042 \\
\hline Methionine & 0.90562 & 0.0048398 & 0.013184 \\
\hline Folic acid & 0.84262 & 0.0055765 & 0.014685 \\
\hline Cytidine monophosphate & 1.1084 & 0.0061877 & 0.015769 \\
\hline Tyrosine & 0.89841 & 0.0077896 & 0.019231 \\
\hline Citrulline & 0.84895 & 0.009764 & 0.023375 \\
\hline Tryptophan & 0.89982 & 0.010347 & 0.02404 \\
\hline Gluconic acid & 1.1258 & 0.013037 & 0.029427 \\
\hline Asparagine & 1.2753 & 0.02567 & 0.05633 \\
\hline Arginine & 0.87285 & 0.034574 & 0.073094 \\
\hline Deoxyadenosine monophosphate & 1.077 & 0.035159 & 0.073094 \\
\hline
\end{tabular}


Table 2. Fold-change of extracellular metabolites significantly modified by tacrolimus exposure ( $n=12)$ (C.M.: culture media, N.D: not detected, D: detected).

\begin{tabular}{|c|c|c|c|c|c|}
\hline Metabolite & Fold-change & P-value (T-test) & FDR & Native C.M. & Interpretation \\
\hline Deoxycytidine & 0.36552 & $1.12 \mathrm{E}-15$ & $6.47 \mathrm{E}-14$ & N.D & Secretion \\
\hline Cytidine & 0.38697 & $2.27 \mathrm{E}-12$ & $6.57 \mathrm{E}-11$ & N.D & Secretion \\
\hline Ornithine & 0.64299 & $1.36 \mathrm{E}-10$ & $2.63 \mathrm{E}-09$ & N.D & Secretion \\
\hline Uridine & 0.47507 & $2.41 \mathrm{E}-09$ & $2.94 \mathrm{E}-08$ & N.D & Secretion \\
\hline Orotic acid & 0.4276 & 2.53E-09 & $2.94 \mathrm{E}-08$ & N.D & Secretion \\
\hline Pyruvic acid & 0.80938 & $6.15 \mathrm{E}-09$ & 5.95E-08 & $\mathrm{D}$ & Secretion \\
\hline Pyridoxal & 0.86522 & $2.81 \mathrm{E}-07$ & $2.33 E-06$ & $\mathrm{D}$ & Secretion \\
\hline $\begin{array}{l}\text { 2-Aminoadipic } \\
\text { acid }\end{array}$ & 0.74831 & $1.88 \mathrm{E}-05$ & 0.00013647 & N.D & Secretion \\
\hline Putrescine & 0.72803 & 3.09E-05 & 0.000199 & $\mathrm{D}$ & Secretion \\
\hline Cystine & 0.84703 & 5.47E-05 & 0.00031711 & $\mathrm{D}$ & Uptake \\
\hline Alanine & 0.78346 & 0.0006475 & 0.003414 & $\mathrm{D}$ & Secretion \\
\hline Lactic acid & 0.91772 & 0.0036161 & 0.017478 & N.D & Secretion \\
\hline Serine & 0.87821 & 0.0088553 & 0.039508 & $\mathrm{D}$ & Secretion \\
\hline Leucine & 1.0455 & 0.018112 & 0.075034 & $\mathrm{D}$ & Uptake \\
\hline Gluconic acid & 0.88113 & 0.023577 & 0.091165 & $\mathrm{D}$ & Uptake \\
\hline Threonine & 0.9359 & 0.028988 & 0.10508 & $\mathrm{D}$ & Uptake \\
\hline
\end{tabular}


MTS

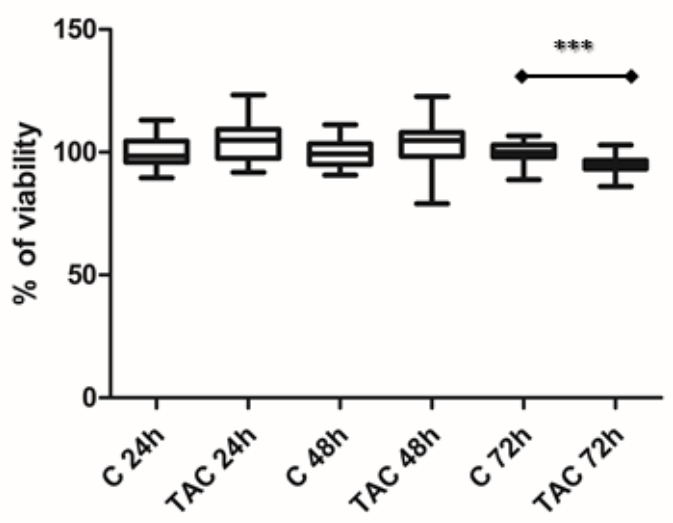

Flow cytometry

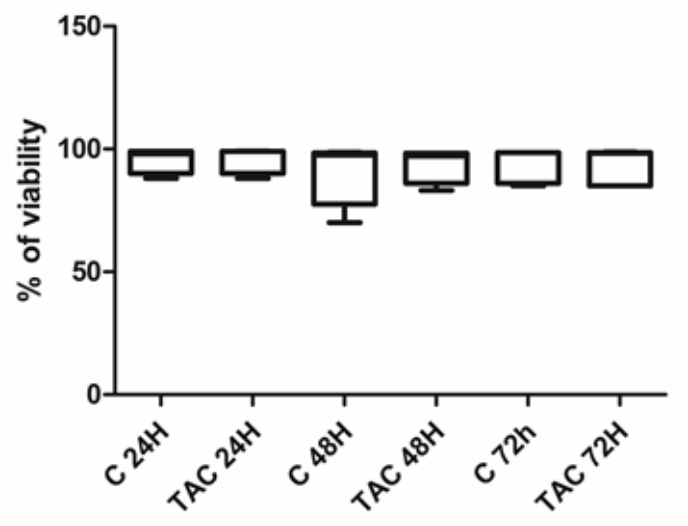

Figure 1 
bioRxiv preprint doi: https://doi.org/10.1101/2021.07.29.454229; this version posted July 30, 2021. The copyright holder for this preprint (which was not certified by peer review) is the author/funder. All rights reserved. No reuse allowed without permission.

A.

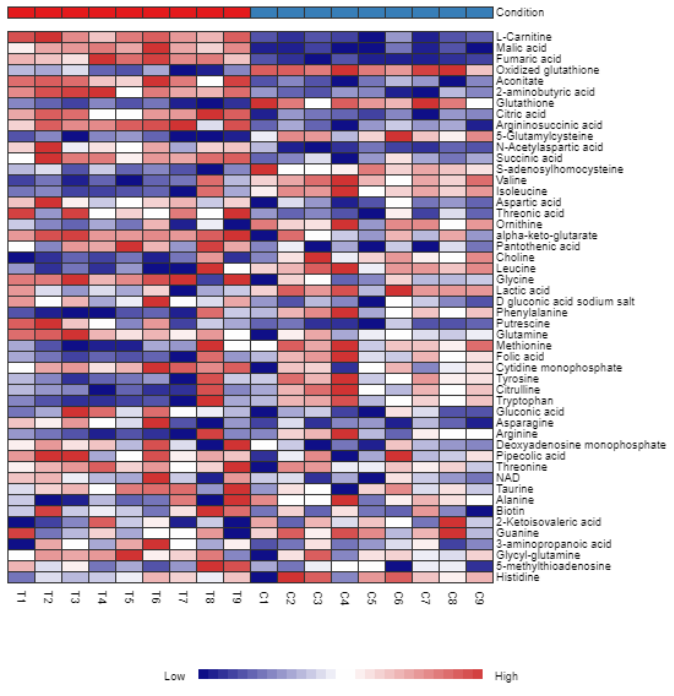

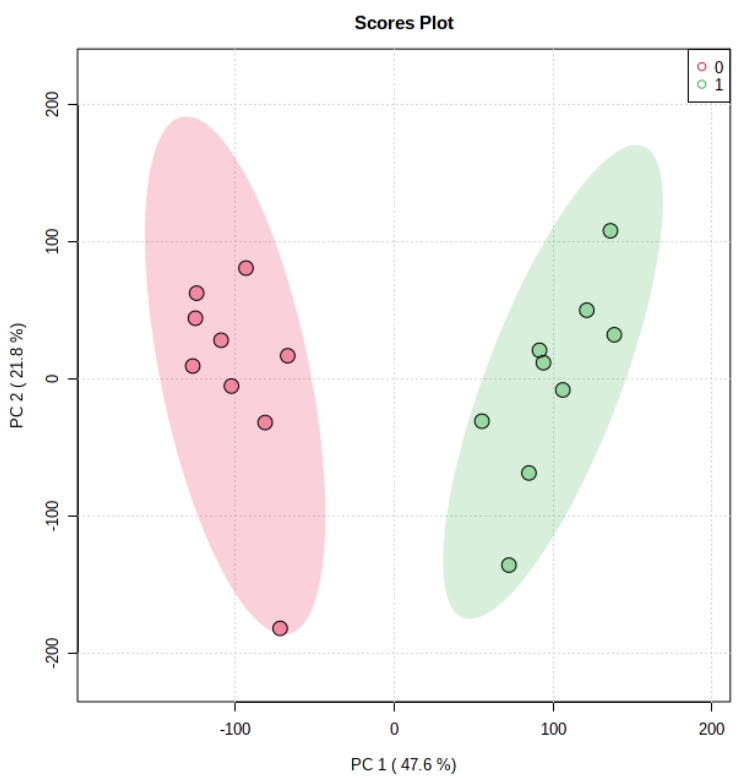

Figure 2 
bioRxiv preprint doi: https://doi.org/10.1101/2021.07.29.454229; this version posted July 30, 2021. The copyright holder for this preprint (which was not certified by peer review) is the author/funder. All rights reserved. No reuse allowed without permission.

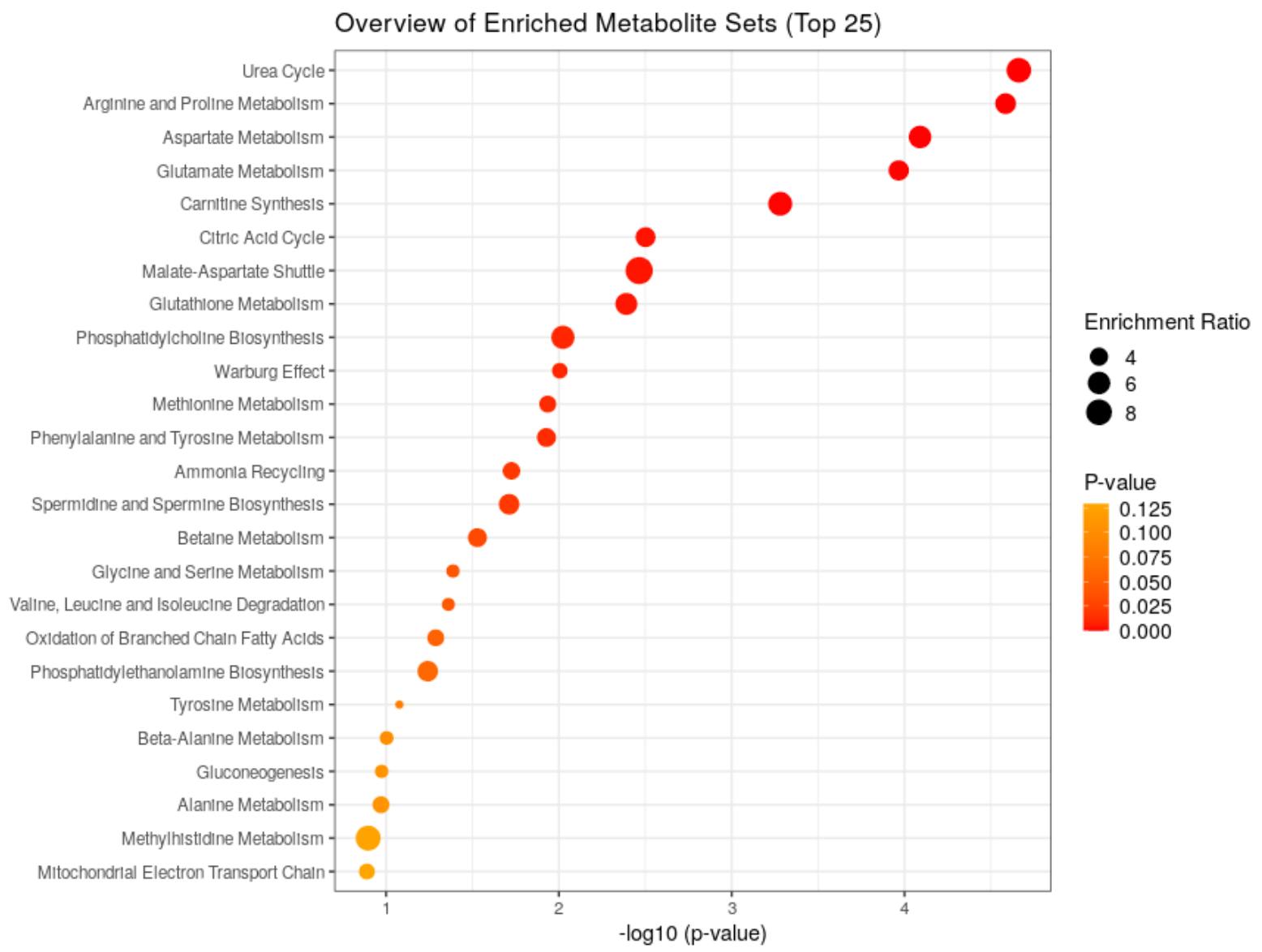

Figure 3 
bioRxiv preprint doi: https://doi.org/10.1101/2021.07.29.454229; this version posted July 30, 2021. The copyright holder for this preprint (which was not certified by peer review) is the author/funder. All rights reserved. No reuse allowed without permission.

A.

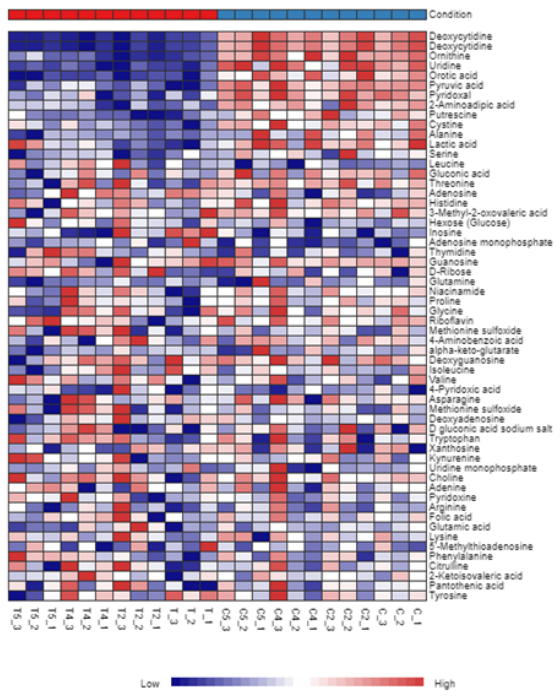

Scores Plot

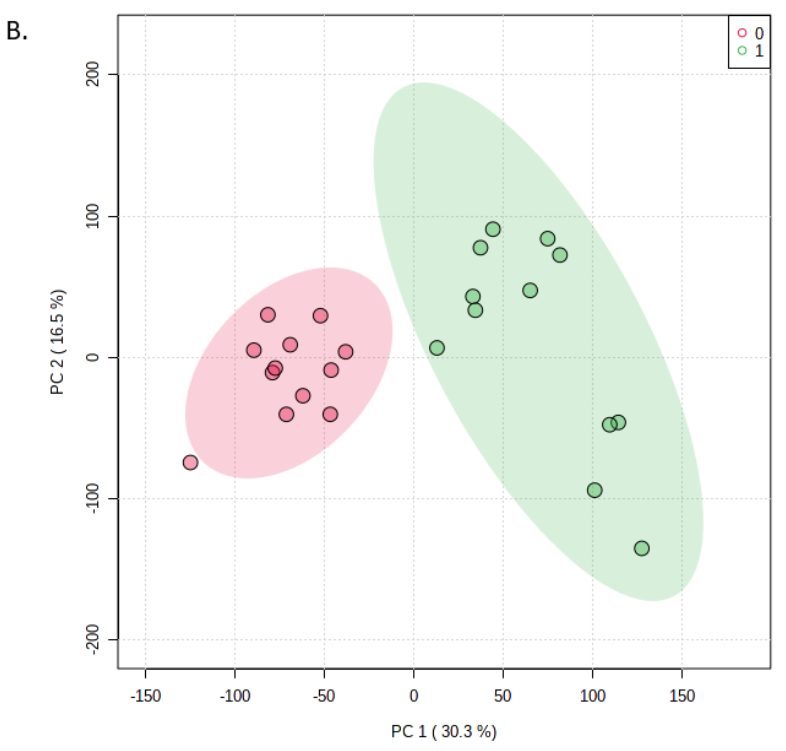

Figure 4 
bioRxiv preprint doi: https://doi.org/10.1101/2021.07.29.454229; this version posted July 30, 2021. The copyright holder for this preprint (which was not certified by peer review) is the author/funder. All rights reserved. No reuse allowed without permission.

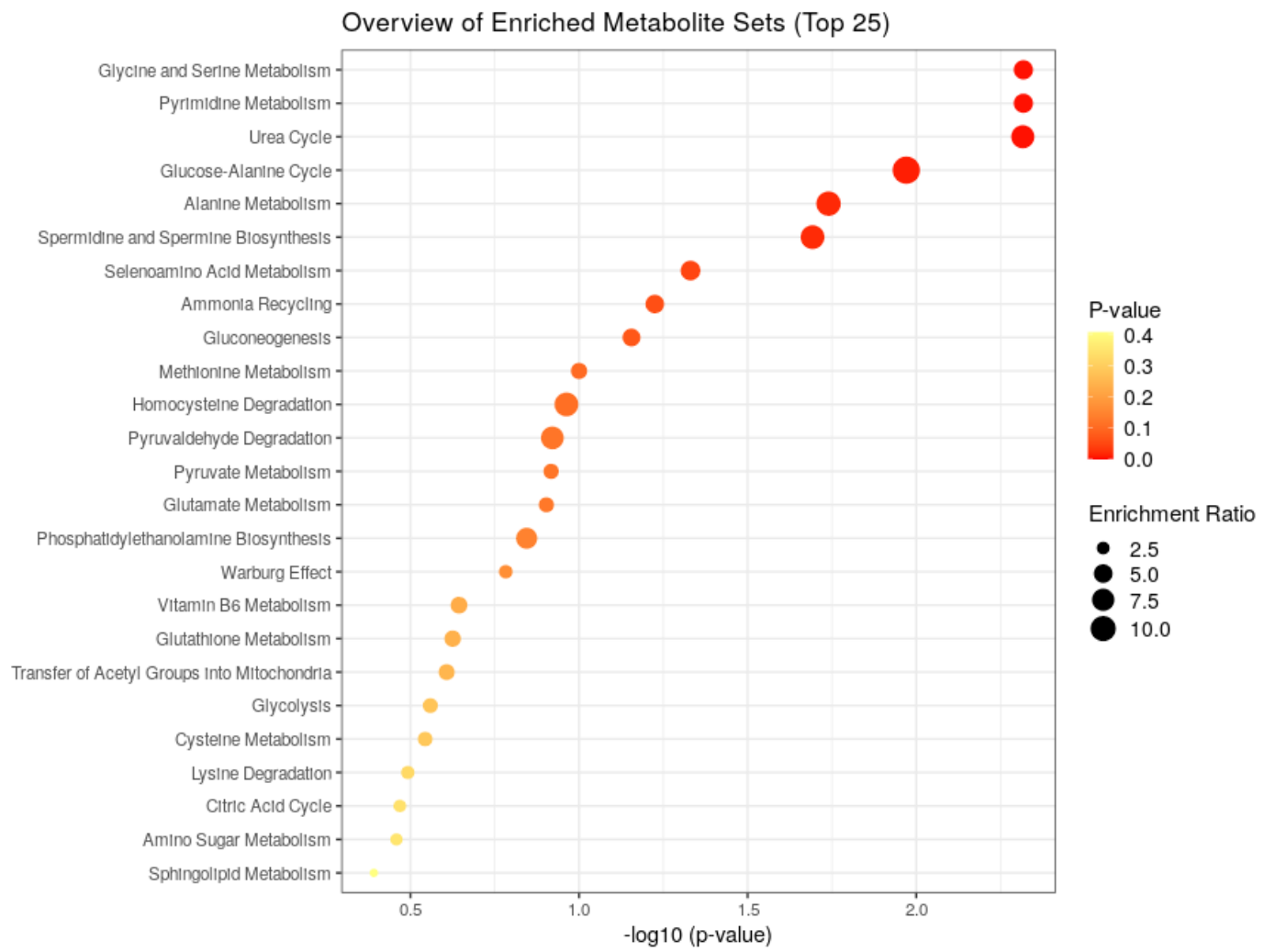

Figure 5 
bioRxiv preprint doi: https://doi.org/10.1101/2021.07.29.454229; this version posted July 30, 2021. The copyright holder for this preprint (which was not certified by peer review) is the author/funder. All rights reserved. No reuse allowed without permission.

\section{Differentially expressed proteins}

Q684M6

K7GPM6

I3LCW1

I3L9M7

F1SM98

F1SID4

F1SGD7

F1S1V1

C0SW08

A5GFS4

A0A287BAWO

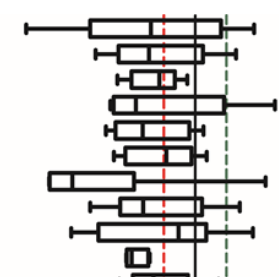

CDC37 cell division cycle 37 protein $O S=S u s$ scrofa $O X=9823$ GN=CDC37 $P E=1 \quad S V=1$

Basal cell adhesion molecule (Lutheran blood group) $O S=S$ s scrofa $O X=9823$ GN=BCAM PE=1 SV= Uncharacterized protein $\mathrm{OS}=\mathrm{Sus}$ scrofa $\mathrm{OX}=9823 \mathrm{GN}=\mathrm{FASN} P E=1 \mathrm{SV}=1$

Leucine rich repeat containing 59 OS=Sus scrofa OX=9823 GN=LRRC59 PE=1 SV=2

Uncharacterized protein $\mathrm{OS}=\mathrm{Sus}$ scrofa $\mathrm{GN}=\mathrm{NDUFV} 2 \mathrm{PE}=4 \mathrm{SV}=1$

Proteasome 26S subunit, ATPase 3 OS=Sus scrofa OX=9823 GN=PSMC3 PE=1 SV=2

Nucleosome assembly protein 1 like $10 S=S u s$ scrofa $O X=9823$ GN=NAP1L1 PE=1 $S V=1$

Sjogren syndrome antigen $B$ OS $=$ Sus scrofa $O X=9823$ GN $=S S B$ PE $=1 \quad S V=3$

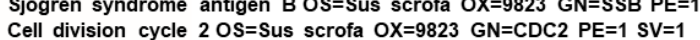

Phosphoenolpyruvate carboxykinase 1 OS=Sus scrofa OX=9823 GN=PCK1 PE=1 SV=1

$\therefore$

0

Uncharacterized protein $O S=S$ s scrofa $O X=9823$ GN=NDUFA5 $P E=1 \quad S V=1$

Delta

Figure 6 

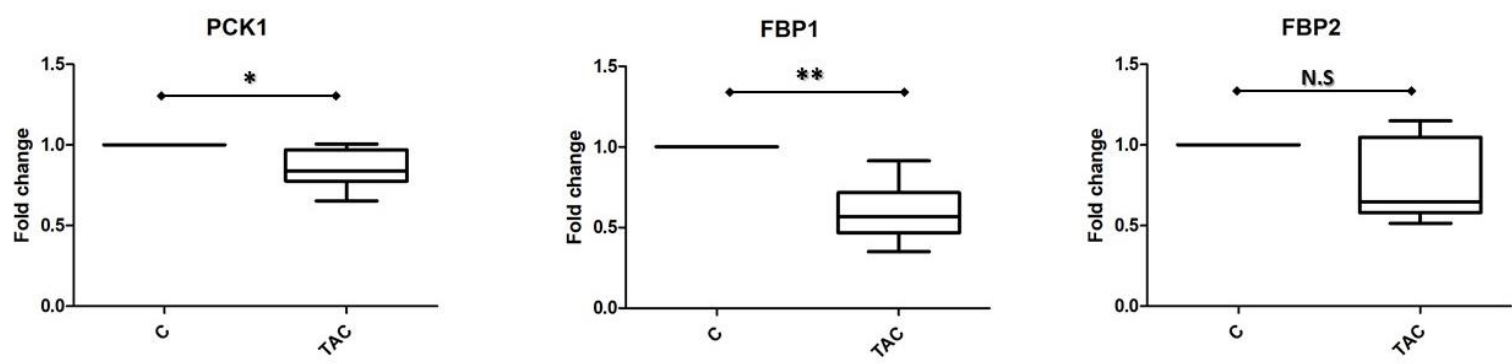

Figure 7 


\section{Tacrolimus}

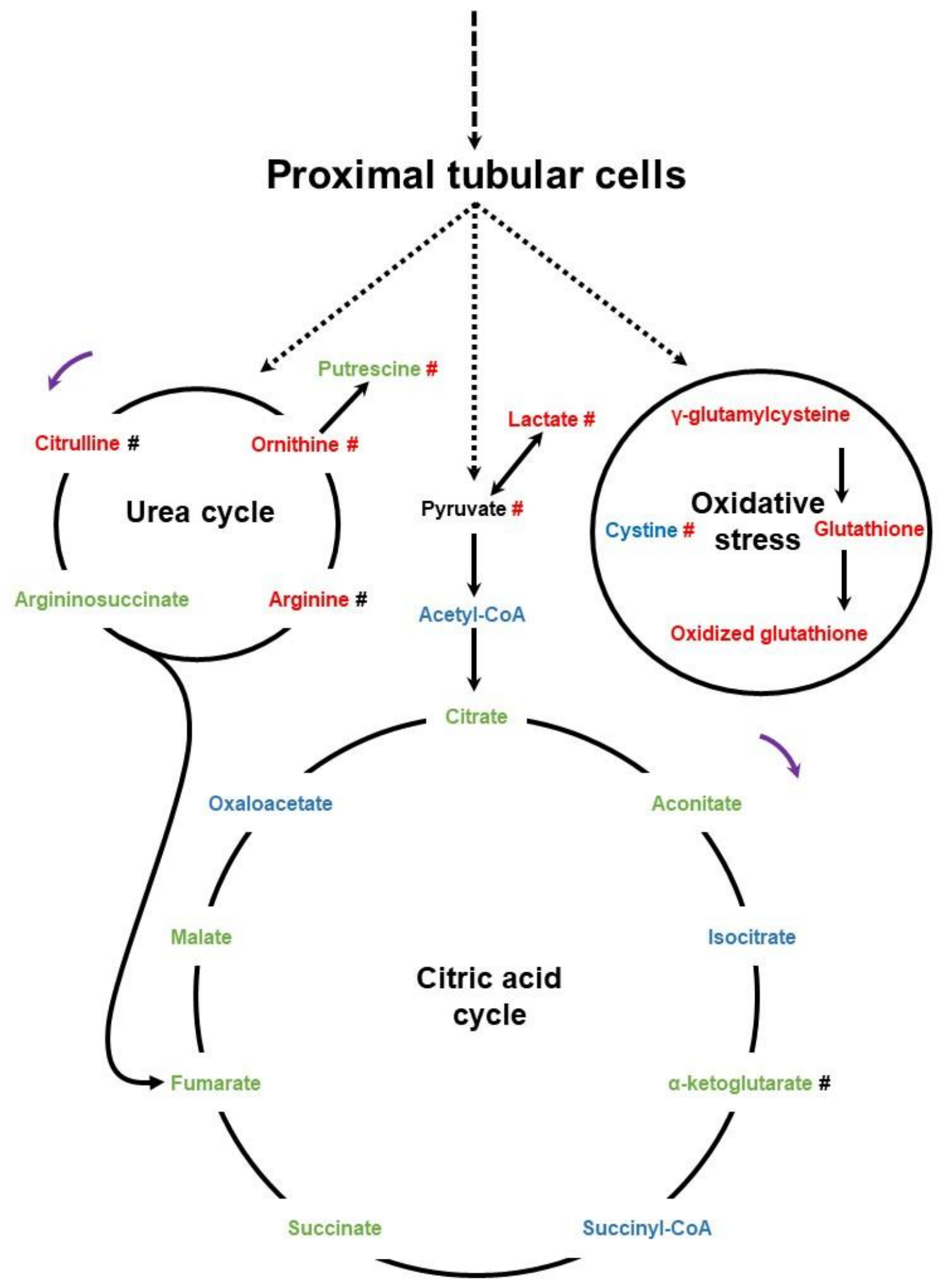

Figure 8 